\title{
Single entity electrochemistry and the electron transfer kinetics of hydrazine oxidation
}

\author{
Ruiyang Miao ${ }^{1}$, Lidong Shao ${ }^{2}$, and Richard G Compton ${ }^{1}$ \\ ${ }^{1}$ Department of Chemistry, Physical and Theoretical Chemistry Laboratory, University of Oxford, South Parks Road, Oxford OX1 3QZ, UK \\ ${ }^{2}$ Shanghai Key Laboratory of Materials Protection and Advanced Materials in Electric Power, Shanghai University of Electric Power, 2103 \\ Pingliang Road, Shanghai 200090, China
}

(c) The Author(s) 2021

Received: 26 November 2020 / Revised: 12 January 2021 / Accepted: 19 January 2021

\section{ABSTRACT}

The mechanism and kinetics of the electro-catalytic oxidation of hydrazine by graphene oxide platelets randomly decorated with palladium nanoparticles are deduced using single particle impact electrochemical measurements in buffered aqueous solutions across the $\mathrm{pH}$ range 2-11. Both hydrazine, $\mathrm{N}_{2} \mathrm{H}_{4}$, and protonated hydrazine $\mathrm{N}_{2} \mathrm{H}_{5}{ }^{+}$are shown to be electroactive following ButlerVolmer kinetics, of which the relative contribution is strongly $\mathrm{pH}$-dependent. The negligible interconversion between $\mathrm{N}_{2} \mathrm{H}_{4}$ and $\mathrm{N}_{2} \mathrm{H}_{5}{ }^{+}$due to the sufficiently short timescale of the impact voltammetry, allows the analysis of the two electron transfer rates from impact signals thus reflecting the composition of the bulk solution at the $\mathrm{pH}$ in question. In this way the rate determining step in the oxidation of each specie is deduced to be a one electron step in which no protons are released and so likely corresponds to the initial formation of a very short-lived radical cation either in solution or adsorbed on the platelet. Overall the work establishes a generic method for the elucidation of the rate determining electron transfer in a multistep process free from any complexity imposed by preceding or following chemical reactions which occur on the timescale of conventional voltammetry.

\section{KEYWORDS}

single entity electrochemistry, hydrazine electro-oxidation, electro-catalysis, graphene oxide, palladium nanoparticles

\section{Introduction}

This paper seeks to develop and illustrate a generic methodology for the study of complex multi-electron electrode processes mediated via nano-particulate materials and to illustrate this with reference to the electro-catalytic oxidation of hydrazine. The electrochemistry of hydrazine, $\mathrm{N}_{2} \mathrm{H}_{4}$, is the focus of current intense and broad interest partly because of the need for chemical sensors $[1,2]$ for this toxic substance but especially because of the scope for its use as the basis of several designs of fuel cells $[3,4]$. In particular the reaction

$$
\mathrm{N}_{2} \mathrm{H}_{4}(\mathrm{l})+\mathrm{O}_{2}(\mathrm{~g})=2 \mathrm{H}_{2} \mathrm{O}(\mathrm{l})+\mathrm{N}_{2}(\mathrm{~g})
$$

has $\Delta G^{\circ}=-623 \mathrm{~kJ} / \mathrm{mol}$ with $\Delta H^{\circ}=-622 \mathrm{~kJ} / \mathrm{mol}$ and $\Delta S^{\circ}=$ $3.3 \mathrm{~J} /(\mathrm{mol} \cdot \mathrm{K})[5]$. These favourable energetics give the basis for fuel cells in which hydrazine is oxidised to nitrogen at the anode whilst the cathodic reaction involves the reduction of oxygen from air to water. In such a cell the choice of optimal electrode materials for both electrodes is challenging and significant efforts have been focused on the four-electron oxidation of hydrazine in aqueous solution

$$
\mathrm{N}_{2}(\mathrm{~g})+5 \mathrm{H}^{+}+4 \mathrm{e}=\mathrm{N}_{2} \mathrm{H}_{5}^{+}(\mathrm{aq})
$$

for which the formal potential is estimated to be $-0.21 \mathrm{~V}$ [6] under conditions of unit proton activity and $-1.46 \mathrm{~V}$ at a $\mathrm{pH}$ of 13. Note that the $\mathrm{pK}_{\mathrm{a}}$ of the $\mathrm{N}_{2} \mathrm{H}_{4} / \mathrm{N}_{2} \mathrm{H}_{5}{ }^{+}$acid-base pair is 8.1 at $298 \mathrm{~K}[7,8]$ so that at $\mathrm{pH} 13$ hydrazine, $\mathrm{N}_{2} \mathrm{H}_{4}$, is not protonated.
Although the four-electron oxidation of hydrazine to nitrogen is highly thermodynamically favourable, as implicit in these data, it is typically electrode kinetically slow with a significant over-potential at most electrodes and this observation drives the need for the design of suitable electro-catalytic anode materials. The oxidation of hydrazine has been studied at a variety of pure metallic electrodes including platinum [9], gold [10] and palladium [11]. It has also been studied at a carbon electrode [12] where there are no significant complications from adsorption effects and at which the reaction involves an initial one-electron oxidation of $\mathrm{N}_{2} \mathrm{H}_{4}$ with fast follow-up chemistry and the electron transfer event shows a potentialdependent transfer coefficient well characterised by Marcus-Hush theory. However, the oxidation on carbon shows a high overpotential whereas this is substantially lowered on other electrode materials in which high-energy intermediates and transition states can be stabilised via adsorption. In all the cases of catalysis via metals such as platinum, gold and silver a major factor is that of the financial cost of the electrode material especially in comparison with carbon-based substrates. Accordingly, work has developed using tiny, minimal quantities of the valuable metals in the form of nanoparticles dispersed over a carbon based substrate. This not only offers economy in the usage of the expensive metals but may offer the additional prospect of altered, preferably improved catalytic behaviour of the nanoparticle in comparison with the bulk metal [13-15].

The material based on nanoparticles supported on a carbon material usually is formed into a composite material which is 
then used as an electrode. Such composites are notoriously difficult to characterise in terms of their intrinsic fundamental electron transfer kinetics at a level other than essentially empirical. The major problem underpinning this is the need to quantitatively describe and decouple the mass transport to and within the composite of uncertain porosity and intrinsic heterogeneity so as to uniquely identify the electron transfer kinetics $[16,17]$. In particular, and notoriously, the development of "thin layer" diffusion within electroactive composites gives the impression of electrochemical reversibility so precluding extraction of any electrode kinetic effects [18-20].

In the case of composites comprised of an aggregated ensemble of single carbon particles themselves decorated with metallic nanoparticles, one approach to circumvent the issues with composites and porous layers is to explore the behaviour of the component decorated particles at the single entity level where the mass transport is well understood. Thus in the present paper we seek to explore the kinetics and mechanism of the oxidation of hydrazine at crudely square-shaped graphene oxide (GO) nano-platelets (of dimensions ca. 3.1 $\mu \mathrm{m}$ in length and $3 \mathrm{~nm}$ in thickness corresponding to 2-5 layers [21-23]) of GO which themselves have been decorated with quasi-spherical palladium nanoparticles of ca. $2.7 \mathrm{~nm}$ in diameter. Figure 1 shows a schematic diagram of the Pd nanoparticles decorated graphene oxide ( $\mathrm{Pd} / \mathrm{GO})$ particle surface. Thus, in practical the GO nano-platelets are used to support the nano-particulate Pd catalyst and the decorated platelets themselves are formed into a composite which coats an electrode used to apply a potential to the porous composite.

In this paper we use "nano-impact" experiments [24-26] to measure the kinetics and mechanism of the oxidation of hydrazine at $\mathrm{Pd} / \mathrm{GO}$ platelets at the single entity level. In a nano-impact experiment an electrode is immersed in a suspension of the entities of interest, specifically $\mathrm{Pd} / \mathrm{GO}$ nano-platelets in the present case, and these particles occasionally impact the electrode by virtue of their random, Brownian motion. The impacting particles can make transient electrical contact with the electrode for the duration of the impact which can last from a few milliseconds to tens or even hundreds of seconds in the case of carbon nanotubes [27]. In this situation for the time of the impact, the collided particle acts as a tiny electrode of a size corresponding to that of the particle itself and, if the solution contains species such as $\mathrm{N}_{2} \mathrm{H}_{4}$ in the present case to which the particle is electro-catalytic then currents can flow if suitable potentials are applied to the immersed electrode. In the case of $\mathrm{Pd} / \mathrm{GO}$ platelets impacting an electrode in an aqueous solution of hydrazine the impact is characterised by on-off steps in the current with each switching event corresponding to the arrival or departure of a single platelet from the electrode-solution interface. The magnitude of the current flowing is explored as a function of the applied potential and the solution composition and conditions, especially $\mathrm{pH}$,

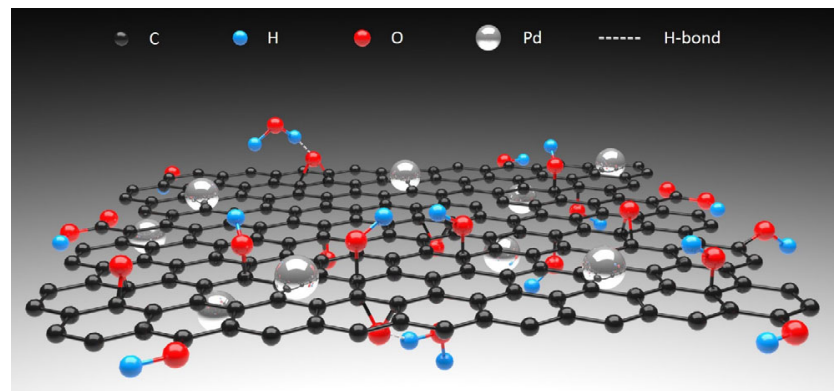

Figure 1 Schematic diagram of the monolayer Pd/GO nanoplatelets. thus revealing the kinetics and mechanism of the hydrazine oxidation at the platelets. In this way a generic methodology is established and illustrated for deducing the rate determining electron transfer step in a complex multi-electron process with coupled chemical reactions mediated via nanomaterials.

\section{Experimental}

\subsection{Chemicals}

Potassium monohydrogen phosphate $\left(\mathrm{K}_{2} \mathrm{HPO}_{4}, 98 \%\right)$, potassium dihydrogen phosphate $\left(\mathrm{KH}_{2} \mathrm{PO}_{4}, 99 \%\right)$, potassium hydroxide $(\mathrm{KOH}, 85 \%)$, potassium nitrate $\left(\mathrm{KNO}_{3}, 99.99 \%\right)$, nitric acid $\left(\mathrm{HNO}_{3}, 70 \%\right)$ and $\mathrm{N}_{2} \mathrm{H}_{4}(99 \%)$ were purchased from SigmaAldrich (Dorest, UK), and used as received. Phosphate buffer solutions of a total concentration $0.1 \mathrm{M}$ were used for the $\mathrm{pH}$ range 7-11, of which the compositions for each is presented in Section S1 in the Electronic Supplementary Material (ESM). A solution of $10 \mathrm{mM} \mathrm{HNO}_{3}$ supported by $0.1 \mathrm{M} \mathrm{KNO}_{3}$ was used for $\mathrm{pH}$ 2. Hydrazine oxidation at higher $\mathrm{pHs}$ using $\mathrm{PBS}$ buffer solutions with higher concentration (e.g., 0.3 M PBS, 0.5 M phosphate buffered saline (PBS) and $0.5 \mathrm{M}$ PBS with $0.2 \mathrm{M}$ potassium chloride), as investigated previously [12], displayed similar electrochemical responses. All solutions were prepared with deionised water (of resistivity $18.2 \mathrm{M} \Omega \cdot \mathrm{cm}$, Millipore, $25^{\circ} \mathrm{C}$ ). All electrochemical experiments (cyclic voltammetry (CV) and chronoamperometry) were conducted in a Faraday cage with an Autolab II potentiostat (Metrohm Autolab, B.V., The Netherlands) at $298 \mathrm{~K}$.

\subsection{Synthesis and characterization of $\mathrm{Pd} / \mathrm{GO}$ particles}

A dispersion of $400 \mathrm{mg}$ graphite oxide, synthesized from natural purified graphite by the Hummers method [28], in $800 \mathrm{~mL}$ distilled water was prepared and then sonicated for 2 h. $240 \mu \mathrm{g}$ palladium nitrate was dissolved in $10 \mathrm{~mL}$ distilled water, and mixed with the dispersion of graphite oxide. Further sonication was carried out for $30 \mathrm{~min}$ to obtain a welldispersed solution, and dried by lyophilisation (freeze-drying, a low temperature dehydration process) so to form a highly exfoliated sample. Subsequently, the sample was collected and placed in a furnace at $500{ }^{\circ} \mathrm{C}$ under vacuum for $0.5 \mathrm{~h}$. The final product, $\mathrm{Pd} / \mathrm{GO}$, was obtained through a further reduction treatment conducted at $250{ }^{\circ} \mathrm{C}$ under a $\mathrm{H}_{2} / \mathrm{He}$ atmosphere for $1 \mathrm{~h}$.

\subsection{Cyclic voltammetry of hydrazine oxidation at a $\mathrm{Pd} / \mathrm{GO}$ modified GC electrode}

$1.0 \mathrm{mg} \mathrm{Pd} / \mathrm{GO}$ was added into $5 \mathrm{~mL}$ deionized water and sonicated for $15 \mathrm{~min}$ to obtain a well-dispersed suspension with a palladium concentration of ca. $5.2 \times 10^{-7} \mathrm{M}$. A glassy carbon (GC) electrode (diameter: ca. $3.0 \mathrm{~mm}$ ) was polished with three grades of successively finer alumina powder $(1.0,0.3$ and $0.05 \mu \mathrm{m}$ ), followed by sonication in an ultrasonic bath for $1 \mathrm{~min}$ and drying with nitrogen. $7 \mu \mathrm{L} \mathrm{Pd} / \mathrm{GO}$ suspension was then drop-cast onto the GC electrode and dried under a $\mathrm{N}_{2}$ atmosphere. The prepared electrode served as a working electrode with the reference electrode (SCE) and the counter electrode (graphite rod) completing the circuit. The estimated coverage of $\mathrm{Pd} / \mathrm{GO}$ nanoplatelets is $7.1 \times 10^{-9} \mathrm{~mol} / \mathrm{cm}^{2}$, the thickness of which is around five layers. $5 \mathrm{~mL}$ of $0.1 \mathrm{M}$ PBS ( $\mathrm{pH} 8.1$ ) containing $1.5 \mathrm{mM} \mathrm{N}_{2} \mathrm{H}_{4}$ was vigorously bubbled with $\mathrm{N}_{2}$ for 15 min prior to the CV measurements and an atmosphere of $\mathrm{N}_{2}$ was maintained during the experiment. A control experiment was performed in the same solution but on a bare GC electrode. 


\subsection{Chronoamperometry of hydrazine oxidation on individual Pd/GO particles}

A carbon fibre microwire electrode [29] of $7 \mu \mathrm{m}$ in diameter and $1 \mathrm{~mm}$ in length functioned as the working electrode whilst the reference and counter electrodes were as mentioned above. $5 \mathrm{~mL}$ of the appropriate buffer solution (see above and Section S1 in the ESM) containing $1.5 \mathrm{mM}$ hydrazine was degassed with $\mathrm{N}_{2}$ for 15 min to remove the dissolved oxygen, followed by the addition of the suspension to form a final solution with $1.1 \times 10^{-14} \mathrm{M} \mathrm{Pd} / \mathrm{GO}$ while $\mathrm{N}_{2}$ kept bubbling for $10 \mathrm{~s}$ to make it well-dispersed. Chronoamperometry with the duration of $20 \mathrm{~s}$ for each scan was recorded in succession after the microwire electrode was inserted into the suspension. A control experiment was conducted as above but without the addition of the $\mathrm{Pd} / \mathrm{GO}$ suspension. Note that the potentiostat used herein enables an accurate conservation of the overall charge transferred in an "nano-impact" event [30].

\section{Results and discussion}

The catalytic ability of the sample Pd/GO was first discussed by comparing the electrochemical responses of $\mathrm{CV}$ from between the bare GC electrode and the Pd/GO modified via dropcast. Then the nano-impact method was employed to study the electroactivity of protonated hydrazine $\left(\mathrm{N}_{2} \mathrm{H}_{5}{ }^{+}\right)$and $\mathrm{N}_{2} \mathrm{H}_{4}$ at $\mathrm{pH} 2$ and 11 respectively where the solution exclusively contained one only of the two species, and the kinetics of their oxidation catalysed by the single entity of Pd/GO assisted with DIGISIM simulation. This enables the study of hydrazine oxidation at intermediate $\mathrm{pH}$ values of 7-8.8 where the oxidation of both $\mathrm{N}_{2} \mathrm{H}_{4}$ and $\mathrm{N}_{2} \mathrm{H}_{5}{ }^{+}$contributes to the electrochemical signal. The interpretation is simplified by the tiny size of the particles which imposes an extremely short timescale for diffusion. This is so short that the dissociation of protonated hydrazine or the protonation of $\mathrm{N}_{2} \mathrm{H}_{4}$ can be neglected on the voltammetric timescale of the nano-impact experiments. The current-potential response reflects simply reflects the composition of the bulk solution as dictated by its $\mathrm{pH}$.

\subsection{Characterization of the Pd/GO nanoplatelets}

The Pd/GO nanoplatelets were characterized by transmission electron microscopy (TEM, FEI Tecnai G2 F20). Figure 2 displays the lamellate morphology of the sample Pd/GO (3.1 \pm $0.2 \mu \mathrm{m}$ in length and ca. $3 \mathrm{~nm}$ in thickness comprised of several layers), whilst spheroidal Pd nanoparticles $(2.7 \pm 0.2 \mathrm{~nm}$ in diameter) were observed to be randomly immobilized on the surface of the platelets, of which the distributions were discussed in detail previously $[31,32]$. The weight loading of Pd was determined to be $5.5 \%$ via inductively coupled plasma (ICP), and its surface density was measured to be $1.1 \times 10^{4} \mu \mathrm{m}^{-2}$ by the software ImageJ.

\subsection{Demonstration of the electro-catalytic ability of Pd/GO using Pd/GO modified electrodes}

To investigate the electrochemical oxidation of hydrazine at the Pd/GO platelets, CV at bare and Pd/GO modified GC electrodes was conducted in $1.5 \mathrm{mM}$ aqueous solutions of hydrazine supported by $0.1 \mathrm{M}$ PBS ( $\mathrm{pH}$ 8.1). As illustrated in Fig. 3, irreversible voltammetric features corresponding to the four-electron hydrazine oxidation $[33,34]$ were observed at both electrodes. The oxidative peak at a scan rate of $50 \mathrm{mV} / \mathrm{s}$ appears at $0.81 \mathrm{~V}$ vs. SCE for the bare electrode (dashed line), while that for the modified electrode (solid line) is seen at $-0.14 \mathrm{~V}$ vs. SCE with a noticeably lower over-potential. Meanwhile, the peaks from the Pd/GO electrode, at all scan rates, display slightly larger anodic currents compared to those from the bare electrode. The latter have a low, potentialdependent transfer coefficient resulting in a peculiarly elongated shape as reported and explained elsewhere [12]. Comparison of the two sets of curves in Fig. 3 demonstrates the ability of $\mathrm{Pd} / \mathrm{GO}$ to effectively catalyse hydrazine oxidation that is attributed in part to the high specific surface area of Pd nanoparticles as well as the excellent electro-catalytic behaviour of Pd noted in Refs. [35, 36].

\subsection{Direct oxidation of $\mathrm{N}_{2} \mathrm{H}_{4}$ and $\mathrm{N}_{2} \mathrm{H}_{5}{ }^{+}$: Nano impact experiments}

Impact electrochemistry was conducted to probe into the thermodynamics and kinetics of hydrazine oxidation via measuring the Faradaic charge transfer from the catalytic current amplification-mediated electron transfer during the collision of individual particles with an electrode [37, 38]. A clean carbon fibre electrode was inserted into a suspension of $\mathrm{Pd} / \mathrm{GO}$ particles $\left(6.6 \times 10^{6} \mathrm{~cm}^{-3}\right)$ supported by $10 \mathrm{mM} \mathrm{HNO}_{3}$ and $0.1 \mathrm{M} \mathrm{KNO}_{3}$ of $\mathrm{pH} 2$ as described in Experimental section and separately for comparison into a "blank" $\mathrm{HNO}_{3}$ solution without particles. At $\mathrm{pH} 2$ the hydrazine exists essentially exclusively in its protonated form, $\mathrm{N}_{2} \mathrm{H}_{5}{ }^{+}$. Upon immersion current-time transients were recorded at an applied potential of $0.75 \mathrm{~V}$ vs. SCE. As illustrated in Figs. 4(a) and 4(b), clear Faradaic current steps were seen with a magnitude of around $0.13 \mathrm{nA}$ in the presence of Pd/GO (red line) whereas no steps or spikes observed in the absence of $\mathrm{Pd} / \mathrm{GO}$ nano-platelets (black line). This indicates that the impact of single $\mathrm{Pd} / \mathrm{GO}$ particles on the microwire surface leads to the catalytic oxidation of protonated hydrazine $\mathrm{N}_{2} \mathrm{H}_{5}{ }^{+}$by electron transfer from the electrode. The fluctuations in current may be caused by the nanoscopic motion of the particle on the electrode

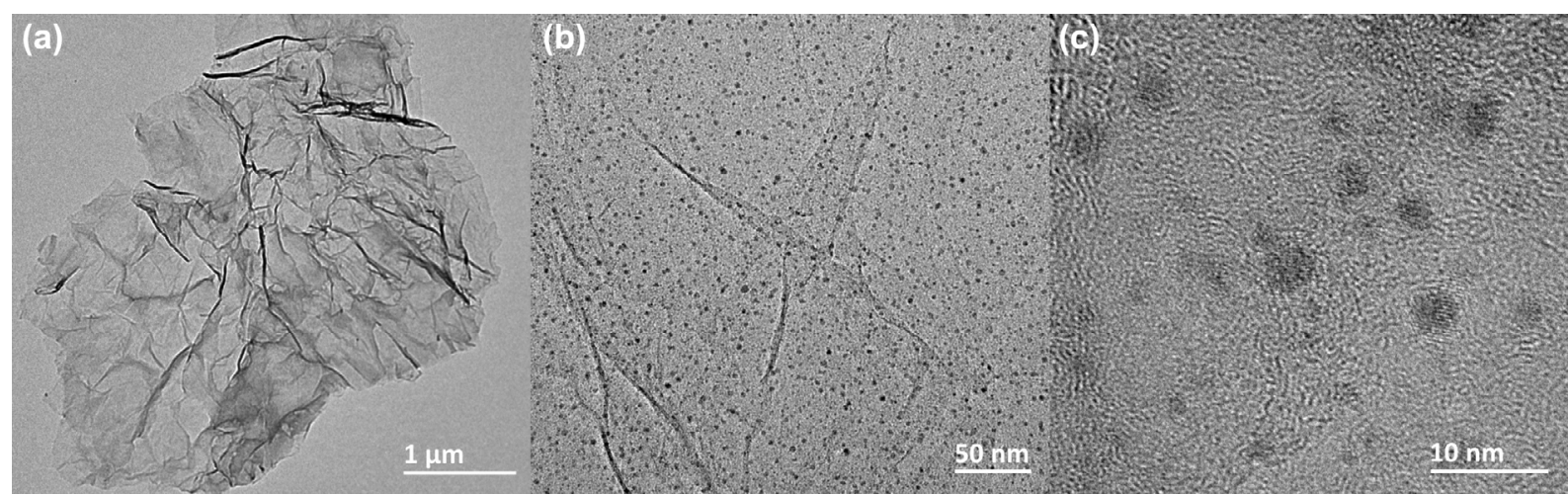

Figure 2 TEM images of (a) Pd/GO nanoplatelets with a scale bar of $1 \mu \mathrm{m}$, (b) Pd/GO nanoplatelets with a scale bar of $50 \mathrm{~nm}$ and (c) Pd nanoparticles decorated on the GO nanoplatelets with a scale bar of $10 \mathrm{~nm}$. 


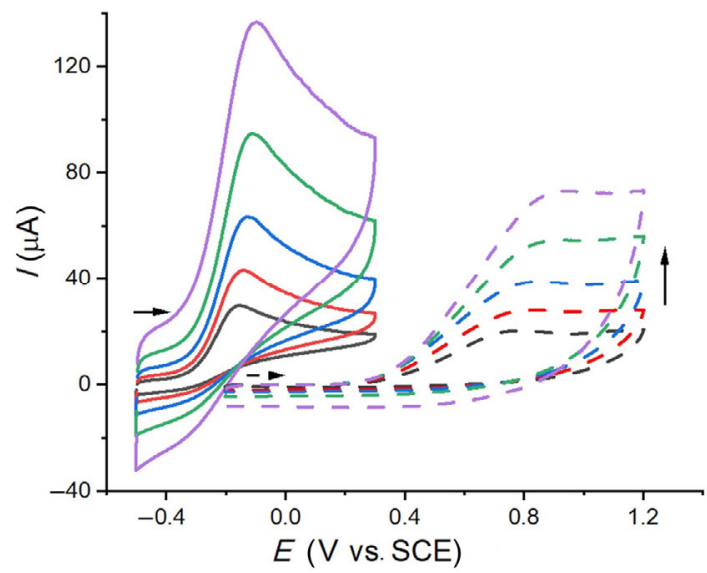

Figure 3 Voltammetry at a bare GC electrode (dashed line) and a Pd/GO modified electrode (solid line) in $0.1 \mathrm{M} \mathrm{PBS}$ ( $\mathrm{pH} 8.1$ ) with $1.5 \mathrm{mM} \mathrm{N}_{2} \mathrm{H}_{4}$. Scan rates: $25,50,100,200$, and $400 \mathrm{mV} / \mathrm{s}$. The vertical arrow indicates increasing scan rates. The transverse arrow indicates the start of the voltammetric scans.

surface that likely brings about the variation of the electrical contact, electro-generated nitrogen may also contribute if nano-bubbles are formed [39]. Note that the sustained current following the step associated with the arrival of the $\mathrm{Pd} / \mathrm{GO}$ particles indicates that the latter remains close to the surface of the electrode and is kept in electrical contact for several seconds. The average currents of the individual steps ( $\geq 40$ for each potential) from the collision of $\mathrm{Pd} / \mathrm{GO}$ nano-platelets were measured as a function of the applied potential and the results are shown in Fig. 5(a) (black squares), where a voltammogram-like response is seen with a current plateau of ca. $0.13 \mathrm{nA}$ when the potential exceeds ca. $0.5 \mathrm{~V}$ vs. SCE. Mass transport corrected Tafel analysis [40] was adopted to analyse the characteristic so to numerically extract the transfer coefficient for the electro-oxidation reaction of $\mathrm{N}_{2} \mathrm{H}_{5}{ }^{+}$via a
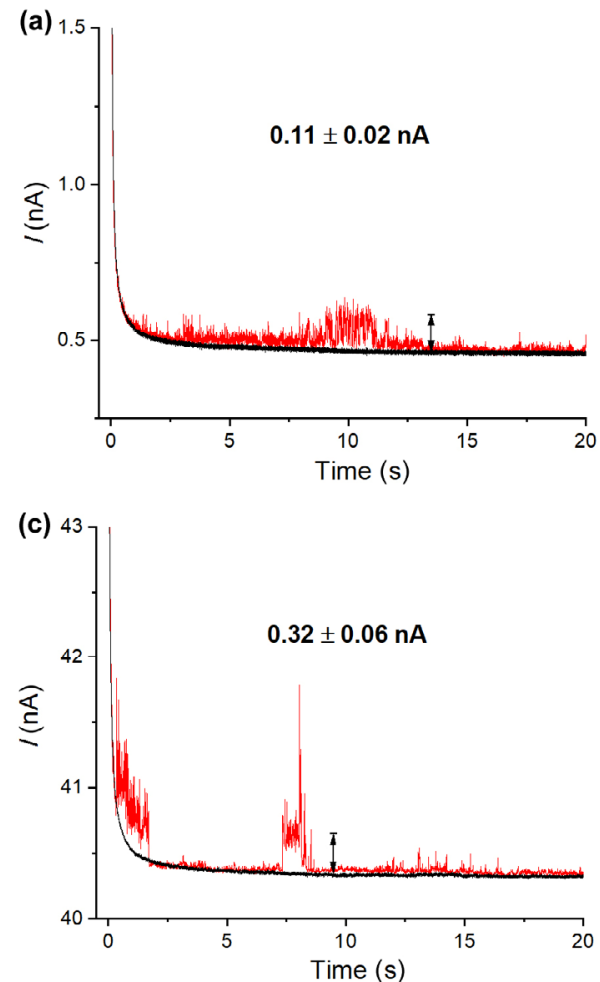

plot of $\ln \left|I-1 / \ln I_{\lim }\right|$ vs. $E$ (Fig. S1(a) in the ESM)

$$
\beta=-\frac{R T}{F} \frac{\mathrm{d} \ln \left(\frac{1}{I}-\frac{1}{I_{\text {lim }}}\right)}{\mathrm{d} E}
$$

where $I$ is the current, $I_{\lim }$ the mass transport limiting current, $E$ the applied potential, $R$ the gas constant, $T$ the absolute temperature and $F$ the Faraday constant. The anodic transfer

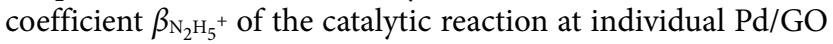
particles was inferred to be $0.41 \pm 0.05$ with the implication that the electrode reaction is fully electrochemically irreversible. Note that for a multi-electron process the apparent transfer coefficient is given by $n^{\prime}+\beta$ [41] where $n^{\prime}$ is the number of electrons preceding the rate determining step and $\beta$ is the transfer coefficient of the rate determining step. Thus the observed value is consistent with $n^{\prime}=0$ and the measured $\beta$ value is close to 0.5 . Since no electrons precede the slowest step the first electron transfer is the rate-determining step [42, 43].

Analogous impact experiments were performed for the direct oxidation of unprotonated $\mathrm{N}_{2} \mathrm{H}_{4}$ in $1.5 \mathrm{mM}$ solution of hydrazine supported by $0.1 \mathrm{M}$ PBS of $\mathrm{pH} 11$ as presented in Figs. 4(c) and 4(d) where a potential of $0.35 \mathrm{~V}$ vs. SCE is applied and the high $\mathrm{pH}$ ensures that the hydrazine is exclusively present in its deprotonated form, $\mathrm{N}_{2} \mathrm{H}_{4}$. Figure 5(a) (aquamarine squares) again manifests a voltammogram-like feature with a plateau at ca. $0.31 \mathrm{nA}$ from $0.15 \mathrm{~V}$ vs. SCE. The corresponding $\beta_{\mathrm{N}_{2} \mathrm{H}_{4}}$ value was estimated to be $0.45 \pm 0.08$ again (Fig. $\mathrm{S} 1$ (b) in the ESM) corresponding to the fully electrochemically irreversible limit and a rate determining first electron transfer.

The electrical contact between the $\mathrm{Pd} / \mathrm{GO}$ nanoplatelets and the electrode during the impact collision, as discussed in our previous work [31], occurs at one of the edges of the platelet. For this reason and due to the limited conductivity of the GO, the catalytic activity towards hydrazine oxidation is confined to a zone physically close to the impacting edge. In terms of mass transport, this was shown [31] to be formally equivalent

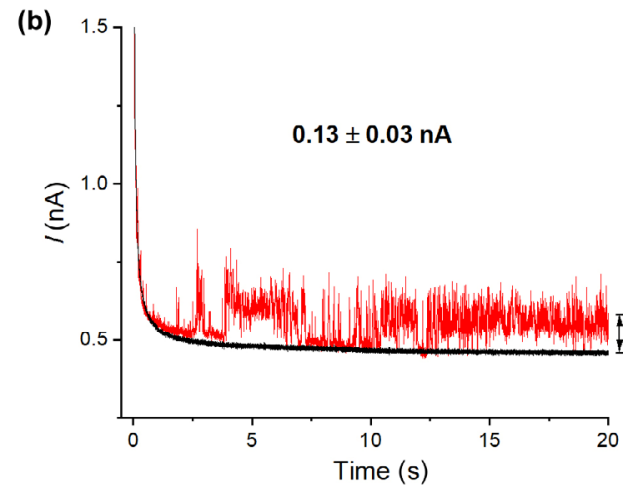

(d)

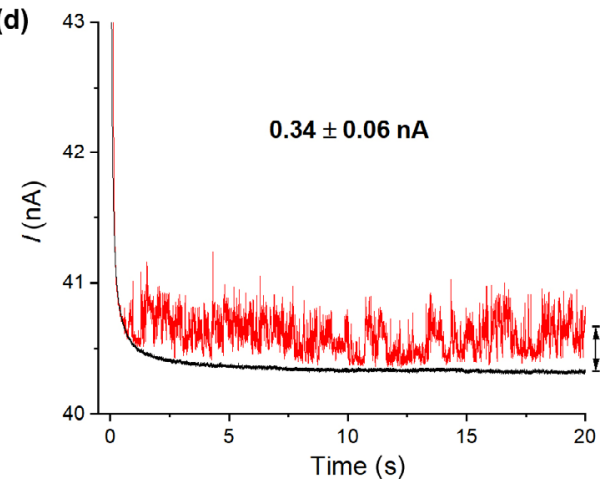

Figure 4 Chronoamperometric profiles showing the Faradaic steps from the direct oxidation of hydrazine catalysed by individual Pd/GO particles impacting on the electrode surface in $1.5 \mathrm{mM}$ aqueous solution of hydrazine. (a) and (b) Supporting electrolyte: $10 \mathrm{mM} \mathrm{HNO}_{3}$ and $0.1 \mathrm{M} \mathrm{KNO}_{3}$ of $\mathrm{pH} 2$, applied potential: $0.75 \mathrm{~V}$ vs. SCE; (c) and (d) supporting electrolyte: $0.1 \mathrm{M}$ PBS of pH 11, applied potential: $0.35 \mathrm{~V}$ vs. SCE. 

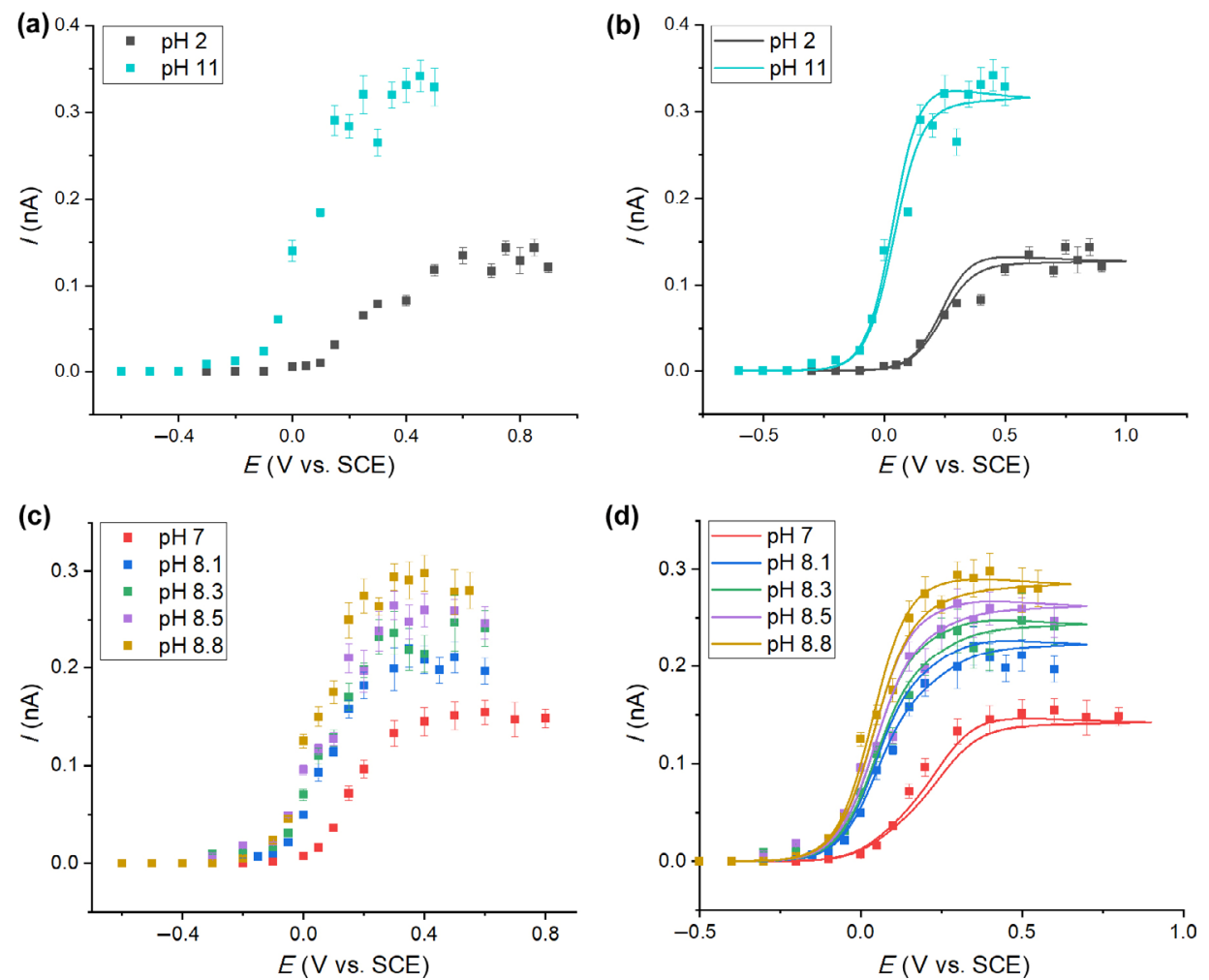

Figure 5 Experimental plots of the average oxidative Faradaic step currents versus applied potentials from nano impacts in the solutions of (a) black squares: $1.5 \mathrm{mM}$ hydrazine supported by $10 \mathrm{mM} \mathrm{HNO}_{3}$ and $0.1 \mathrm{M} \mathrm{KNO}_{3}$ of $\mathrm{pH} 2$, aquamarine squares: $1.5 \mathrm{mM}$ hydrazine supported by $0.1 \mathrm{M} \mathrm{PBS}$ of pH 11; (c) $1.5 \mathrm{mM}$ hydrazine supported by $0.1 \mathrm{M}$ PBS of the intermediate $\mathrm{pH} 7,8.1,8.3,8.5$, and 8.8. DIGISIM-simulated curves of (b) black line: $\mathrm{N}_{2} \mathrm{H}_{5}{ }^{+}$ oxidation at $\mathrm{pH} 2$, aquamarine line: $\mathrm{N}_{2} \mathrm{H}_{4}$ oxidation at $\mathrm{pH} 11$; (d) concurrent oxidation of $\mathrm{N}_{2} \mathrm{H}_{5}{ }^{+}$and $\mathrm{N}_{2} \mathrm{H}_{4}$ at $\mathrm{pH} 7,8.1,8.3,8.5$, and 8.8. The input of the forward rate constant is $200 \mathrm{~cm} / \mathrm{s}$. The number of the impacting current steps analysed for each square is $\geq 40$. The error bar is the standard error of the mean.

to a microband electrode with a length of $3.1 \pm 0.2 \mu \mathrm{m}$ and a width of ca. $3.0 \mathrm{~nm}$. Modelling the appropriate mass transport regime [27] allows the inference from the plateau currents seen

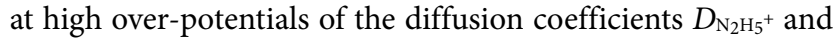
$D_{\mathrm{N}_{2} \mathrm{H}_{4}}$ as $(2.8 \pm 0.3) \times 10^{-6}$ and $(7.1 \pm 0.8) \times 10^{-6} \mathrm{~cm}^{2} / \mathrm{s}$ respectively based on the Aoki equation $[44,45]$ for a micro-band electrode (Section S3 in the ESM).

DIGISIM (version 3.03b, Bioanalytical System, Inc, USA) was then utilized to extract further mechanistic detail of the hydrazine oxidation. DIGSIM is a commercial simulation software built on the innovative, pioneering simulation work of M. Rudolph, based on a fully implicit finite difference method [46]. A hemicylindrical geometry was selected in DIGISIM to approximate a catalytically-active microband, using a length of $3.1 \mu \mathrm{m}$ and an equivalent radius, $r$, of $1.0 \mathrm{~nm}$ from the relationship $r=w / \pi[47,48]$ where $w$ is the width of the microband as previously inferred [31].

The following mechanism was investigated

$$
\begin{gathered}
\mathrm{N}_{2} \mathrm{H}_{5}{ }^{+} \rightleftharpoons \mathrm{N}_{2} \mathrm{H}_{4}+\mathrm{H}^{+} \\
\mathrm{N}_{2} \mathrm{H}_{5}{ }^{+}=\mathrm{N}_{2}+5 \mathrm{H}^{+}+4 \mathrm{e} \\
\mathrm{N}_{2} \mathrm{H}_{4}=\mathrm{N}_{2}+4 \mathrm{H}^{+}+4 \mathrm{e}
\end{gathered}
$$

where the equilibrium constant $K_{\text {eq }}$ for the acid-base reaction between hydrazine and its protonated form is known to be $7.9 \times$ $10^{-9} \mathrm{M}\left(\mathrm{pK}_{\mathrm{a}}=8.1\right.$ at $\left.298 \mathrm{~K}\right)$. Note that the diffusional timescale of the impact experiment corresponds under the microband/ hemicylindrical electrode model employed to voltammetric of $w^{2} / D$ where $D$ is the diffusion coefficient of the electroactive species. This corresponds to a sub-nanosecond duration so that it is expected that the contribution of the acid-base reaction
(1) is negligible and the response reflects the sum of the individual oxidations of hydrazine and protonated hydrazine with concentrations "frozen" at their bulk values. The modelling below shows that the response is indeed the sum of the two forms of hydrazine without interconversion on the experimental timescale.

First however the data at $\mathrm{pH} 2$ was analysed where the reaction was assumed to be exclusively

$$
\mathrm{N}_{2} \mathrm{H}_{5}{ }^{+}=\mathrm{N}_{2}+5 \mathrm{H}^{+}+4 \mathrm{e}
$$

and, where the electrode reaction has a rate determining first electron transfer as implied by the corresponding transfer coefficient inferred above and using the diffusion coefficient for $\mathrm{N}_{2} \mathrm{H}_{5}{ }^{+}$deduced above. This simulation (detailed in Section S4 in the ESM) shows a very satisfactory fit with the experiment as depicted in Fig. 5(b) (black line), confirmed the electrochemical irreversibility and gave a composite parameter of $k_{\mathrm{N}_{2} \mathrm{H}_{5}{ }^{+}}^{0} \mathrm{e}^{-\beta_{\mathrm{N}_{2} \mathrm{H}_{5}} \mathrm{FE}_{\mathrm{f}, \mathrm{N}_{2} \mathrm{H}_{5}{ }^{+}}^{0} / R T}=0.06 \pm 0.02 \mathrm{~cm} / \mathrm{s}$, where $\beta_{\mathrm{N}_{2} \mathrm{H}_{5}{ }^{+}}=0.41$ and the value of $D_{\mathrm{N}_{2} \mathrm{H}_{5}}{ }^{+}=2.8 \times 10^{-6} \mathrm{~cm}^{2} / \mathrm{s}$ as deduced above from the plateau current.

Similarly the data from pH 11 was analysed (detailed in Section S4 in the ESM) exclusively in terms of the process

$$
\mathrm{N}_{2} \mathrm{H}_{4}=\mathrm{N}_{2}+4 \mathrm{H}^{+}+4 \mathrm{e}
$$

again with a rate determining first electron transfer as signalled by the measured transfer coefficient and using the diffusion coefficient deduced above. Figure 5(b) (aquamarine line) shows a good fit between simulation and experiment using a composite rate constant of $k_{\mathrm{N}_{2} \mathrm{H}_{4}}^{0} \mathrm{e}^{-\beta_{\mathrm{N}_{2} \mathrm{H}_{4}} F E_{\mathrm{fN}_{2} \mathrm{H}_{4}}^{0} / R T}=3.3 \pm$ $0.2 \mathrm{~cm} / \mathrm{s}$, where $\beta_{\mathrm{N}_{2} \mathrm{H}_{4}}=0.45$ and $D_{\mathrm{N}_{2} \mathrm{H}_{4}}=7.1 \times 10^{-6} \mathrm{~cm}^{2} / \mathrm{s}$. Note 
that the above-mentioned kinetic data is extracted from the analysis of the impacts from the view of nano-sized entities; extrapolation of the data to bulk Pd is cautioned [41, 49].

\subsection{Concurrent oxidation of $\mathrm{N}_{2} \mathrm{H}_{4}$ and $\mathrm{N}_{2} \mathrm{H}_{5}{ }^{+}$: Nano impact experiments}

Next attention was focused on the full scheme given in reactions (1)-(3). The two electrode reactions were modelled using the data inferred from the conditions as discussed above where the speciation was essentially exclusively one species or the other. This assumption is explored more fully below in respect of the consideration of the bulk $\mathrm{pH}$. Further the level of buffering was assumed to be such that the equilibrium between the different forms was rapidly established in bulk solution but that in the vicinity of the impacted particles the voltammetric timescale is sufficiently short as to preclude re-equilibration between the two forms as discussed above.

The nano impact experiments were performed in the solutions of $1.5 \mathrm{mM}$ hydrazine supported by $0.1 \mathrm{M}$ PBS at the intermediate $\mathrm{pH}$ values from 7 to 8.8 where the electrooxidations of $\mathrm{N}_{2} \mathrm{H}_{4}$ and $\mathrm{N}_{2} \mathrm{H}_{5}{ }^{+}$may both contribute to the measured signals. The relative extent is controlled not only by the equilibrium constants ( $K_{\text {eq }}$, see above), but also, at least in principle, the homogeneous kinetics of the interconversion between the two species. The latter represents a single adjustable parameter in our modelling below. The mean catalytic impact currents under a series of potentials at $\mathrm{pH} 7-8.8$ are presented in Fig. 5(c) where again pH-dependent "steady-state currents" are seen. Upon the rise of $\mathrm{pH}$, the plateau current increases conspicuously in accordance with that observed in Fig. 5(a) due to the increase in the component of $\mathrm{N}_{2} \mathrm{H}_{4}$ which probably on account of being uncharged has a higher diffusion coefficient than protonated hydrazine. Meanwhile, the halfwave potential shifts to more negative potentials reflecting the higher effective composite electrochemical rate constant of $\mathrm{N}_{2} \mathrm{H}_{4}$ oxidation compared to $\mathrm{N}_{2} \mathrm{H}_{5}{ }^{+}$.

Based on reactions (1)-(3) in consideration of the homogeneous reaction of the two species $\mathrm{N}_{2} \mathrm{H}_{5}{ }^{+}$and $\mathrm{N}_{2} \mathrm{H}_{4}$, the simulation for the concurrent oxidation was conducted using the same hemicylindrical geometry with the kinetic parameters derived above. The excellent fittings in Fig. 5(d) confirm the availability of the proposed mechanism at the intermediate pHs (detailed in Section S4 in the ESM) and, importantly as shown in Fig. S2 in the ESM to be effectively independent of the forward and back rate constants of the homogeneous reaction of reaction (1).

The modelling of the data in Fig. 5(d) for the $\mathrm{pH}$ range 7-8.8 shows a good fit using the values for the electrochemical rate constants for the oxidation of hydrazine at $\mathrm{pH} 11$ and of protonated hydrazine at $\mathrm{pH}$ 2. We therefore infer that these values are independent of $\mathrm{pH}$. The mechanistic implications of this observation build on the basis of the expected $\mathrm{pH}$ variation of the electrochemical rate constant for a fully irreversible oxidation (detailed in Section S5 in the ESM). On this consideration, the first electron transfer and also the rate determining step for both the oxidations of the two species $\mathrm{N}_{2} \mathrm{H}_{5}{ }^{+}$and $\mathrm{N}_{2} \mathrm{H}_{4}$ are not associated with the release of protons during the impact event. This suggests therefore the initial formation of the radical cations $\mathrm{N}_{2} \mathrm{H}_{5}{ }^{2+}$ and $\mathrm{N}_{2} \mathrm{H}_{4}{ }^{+}$which survive, either as solution phase or adsorbed species, at least on the voltammetric diffusional timescale of the particle impact (sub-nanoscale), presented as

$$
\mathrm{N}_{2} \mathrm{H}_{5}{ }^{+} \rightleftharpoons \mathrm{N}_{2} \mathrm{H}_{4}+\mathrm{H}^{+}
$$

$$
\begin{aligned}
& \mathrm{N}_{2} \mathrm{H}_{5}{ }^{+} \stackrel{\text { rds }}{\longrightarrow} \mathrm{N}_{2} \mathrm{H}_{5}{ }^{2+}+\mathrm{e} \\
& \mathrm{N}_{2} \mathrm{H}_{5}{ }^{2+} \stackrel{\text { fast }}{\longrightarrow} \mathrm{N}_{2}+5 \mathrm{H}^{+}+3 \mathrm{e} \\
& \mathrm{N}_{2} \mathrm{H}_{4} \stackrel{\text { rds }}{\longrightarrow} \mathrm{N}_{2} \mathrm{H}_{4}{ }^{+}+\mathrm{e} \\
& \mathrm{N}_{2} \mathrm{H}_{4}{ }^{+} \stackrel{\text { fast }}{\longrightarrow} \mathrm{N}_{2}+4 \mathrm{H}^{+}+3 \mathrm{e}
\end{aligned}
$$

Of course the application of Butler-Volmer theory as in Section S5 in the ESM containing mention of a formal potential, or indeed equally Marcus-Hush theory [50, 51] with a similar thermodynamic content and derived from extrapolation to equilibrium conditions is unlikely to be realistic at the timescale under consideration. However it is clear that the rate constants for the hydrazine and protonated hydrazine oxidations are exponentially dependent on potential, are controlled by the first electron transfer and are $\mathrm{pH}$ independent all signalling that on the Pd/GO nanoplatelets the rate determining step is an initial electron transfer creating a radical cation.

\section{Conclusions}

In this work, palladium nanoparticles decorated graphene oxide nanoplatelets (Pd/GO) were utilized as an electro-catalyst towards hydrazine oxidation either as dropcast (ensemble) modified electrodes or as single entities in nano impact experiments in buffered solutions. The direct oxidation of $\mathrm{N}_{2} \mathrm{H}_{4}$ and $\mathrm{N}_{2} \mathrm{H}_{5}{ }^{+}$was investigated at $\mathrm{pH} 2$ and 11 respectively by impact electrochemistry that shows voltammogram-like characteristics with steady-state currents, from which the essential

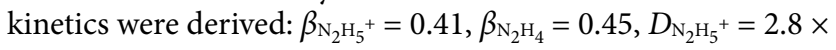
$10^{-6} \mathrm{~cm}^{2} / \mathrm{s}, D_{\mathrm{N}_{2} \mathrm{H}_{4}}=7.1 \times 10^{-6} \mathrm{~cm}^{2} / \mathrm{s}, k_{\mathrm{N}_{2} \mathrm{H}_{5}{ }^{+}}^{0} \mathrm{e}^{-\beta_{\mathrm{N}_{2} \mathrm{H}_{5}}+E_{f, \mathrm{~N}_{2} \mathrm{H}_{5}{ }^{+}} / R T}=$ $0.06 \mathrm{~cm} / \mathrm{s}$ and $k_{\mathrm{N}_{2} \mathrm{H}_{4}}^{0} \mathrm{e}^{-\beta_{\mathrm{N}_{2} \mathrm{H}_{4}} F E_{f, \mathrm{~N}_{2} \mathrm{H}_{4}}^{0} / R T}=3.3 \mathrm{~cm} / \mathrm{s}$. Under the conditions of minimal effect from the interconversion between $\mathrm{N}_{2} \mathrm{H}_{5}{ }^{+}$and $\mathrm{N}_{2} \mathrm{H}_{4}$ due to the ultrashort voltammetric timescale on individual $\mathrm{Pd} / \mathrm{GO}$ particle, the simulation for the nanoimpacts from the intermediate $\mathrm{pHs}$ of 7-8.8 reveals the mechanism for the hydrazine oxidation, the rate determining step that involves no proton release and provides kinetic data for the latter.

Funding note: Open access funding provided by University of Oxford.

Electronic Supplementary Material: Supplementary material (further details of the chemical compositions, Tafel analysis, calculation of diffusion coefficients, DIGISIM simulation and $\mathrm{pH}$ dependency of electrochemical rate constant) is available in the online version of this article at https://doi.org/10.1007/ s12274-021-3353-8.

Open Access This article is licensed under a Creative Commons Attribution 4.0 International License, which permits use, sharing, adaptation, distribution and reproduction in any medium or format, as long as you give appropriate credit to the original author(s) and the source, provide a link to the Creative Commons licence, and indicate if changes were made.

The images or other third party material in this article are included in the article's Creative Commons licence, unless indicated otherwise in a credit line to the material. If material is not included in the article's Creative Commons licence and your intended use is not permitted by statutory regulation or exceeds the permitted use, you will need to obtain permission directly from the copyright holder.

To view a copy of this licence, visit http://creativecommons.org/licenses/by/4.0/. 


\section{References}

[1] Chen, C. H.; Jacobse, L.; McKelvey, K.; Lai, S. C. S.; Koper, M. T. M.; Unwin, P. R. Voltammetric scanning electrochemical cell microscopy: Dynamic imaging of hydrazine electro-oxidation on platinum electrodes. Anal. Chem. 2015, 87, 5782-5789.

[2] Harraz, F. A.; Ismail, A. A.; Al-Sayari, S. A.; Al-Hajry, A.; Al-Assiri, M. S. Highly sensitive amperometric hydrazine sensor based on novel $\alpha-\mathrm{Fe}_{2} \mathrm{O}_{3} /$ crosslinked polyaniline nanocomposite modified glassy carbon electrode. Sens. Actuators B Chem. 2016, 234, 573-582.

[3] Wang, T. Z.; Wang, Q.; Wang, Y. C.; Da, Y. L.; Zhou, W.; Shao, Y.; Li, D. B.; Zhan, S. H.; Yuan, J. Y.; Wang, H. Atomically dispersed semimetallic selenium on porous carbon membrane as an electrode for hydrazine fuel cells. Angew. Chem., Int. Ed. 2019, 131, 1360013605 .

[4] Lu, Z. Y.; Sun, M.; Xu, T. H.; Li, Y. J.; Xu, W. W.; Chang, Z.; Ding, Y.; Sun, X. M.; Jiang, L. Superaerophobic electrodes for direct hydrazine fuel cells. Adv. Mater. 2015, 27, 2361-2366.

[5] Sakamoto, T.; Asazawa, K.; Martinez, U.; Halevi, B.; Suzuki, T.; Arai, S.; Matsumura, D.; Nishihata, Y.; Atanassov, P.; Tanaka, H. Electrooxidation of hydrazine hydrate using $\mathrm{Ni}-\mathrm{La}$ catalyst for anion exchange membrane fuel cells. J. Power Sources 2013, 234, 252-259.

[6] Lindley, B. M.; Appel, A. M.; Krogh-Jespersen, K.; Mayer, J. M.; Miller, A. J. M. Evaluating the thermodynamics of electrocatalytic $\mathrm{N}_{2}$ reduction in acetonitrile. ACS Energy Lett. 2016, 1, 698-704.

[7] Lide, D. R. CRC Handbook of Chemistry and Physics, 85th ed.; CRC Press: Boca Raton, FL, USA, 2004.

[8] Hall, Jr. H. K. Correlation of the base strengths of amines. J. Am. Chem. Soc. 1957, 79, 5441-5444.

[9] Karp, S.; Meites, L. The voltammetric characteristics and mechanism of electroöxidation of hydrazine. J. Am. Chem. Soc. 1962, 84, 906-912.

[10] Álvarez-Ruiz, B.; Gómez, R.; Orts, J. M.; Feliu, J. M. Role of the metal and surface structure in the electro-oxidation of hydrazine in acidic media. J. Electrochem. Soc. 2002, 149, D35-D45.

[11] Burke, L. D.; Casey, J. K. The electrocatalytic behaviour of palladium in acid and base. J. Appl. Electrochem. 1993, 23, 573-582.

[12] Miao, R. Y.; Chen, L. F.; Compton, R. G. Electro-oxidation of hydrazine shows marcusian electron transfer kinetics. Sci. China Chem. 2021, 64, 322-329.

[13] Wang, Y.; Laborda, E.; Tschulik, K.; Damm, C.; Molina, A.; Compton, R. G. Strong negative nanocatalysis: Oxygen reduction and hydrogen evolution at very small $(2 \mathrm{~nm})$ gold nanoparticles. Nanoscale 2014, 6, 11024-11030.

[14] Wang, Y.; Ward, K. R.; Laborda, E.; Salter, C.; Crossley, A.; Jacobs, R. M. J.; Compton, R. G. A joint experimental and computational search for authentic nano-electrocatalytic effects: Electrooxidation of nitrite and L-ascorbate on gold nanoparticle-modified glassy carbon electrodes. Small 2013, 9, 478-486.

[15] Yang, W. X.; Liu, X. J.; Yue, X. Y.; Jia, J. B.; Guo, S. J. Bamboo-like carbon nanotube/ $\mathrm{Fe}_{3} \mathrm{C}$ nanoparticle hybrids and their highly efficient catalysis for oxygen reduction. J. Am. Chem. Soc. 2015, 137, 14361439.

[16] Kätelhön, E.; Chen, L. F.; Compton, R. G. Nanoparticle electrocatalysis: Unscrambling illusory inhibition and catalysis. Appl. Mater. Today 2019, 15, 139-144.

[17] Chen, L. F.; Kätelhön, E.; Compton, R. G. Particle-modified electrodes: General mass transport theory, experimental validation, and the role of electrostatics. Appl. Mater. Today 2020, 18, 100480.

[18] Streeter, I.; Wildgoose, G. G.; Shao, L. D.; Compton, R. G. Cyclic voltammetry on electrode surfaces covered with porous layers: An analysis of electron transfer kinetics at single-walled carbon nanotube modified electrodes. Sens. Actuators B Chem. 2008, 133, 462-466.

[19] Henstridge, M. C.; Dickinson, E. J. F.; Aslanoglu, M.; BatchelorMcAuley, C.; Compton, R. G. Voltammetric selectivity conferred by the modification of electrodes using conductive porous layers or films: The oxidation of dopamine on glassy carbon electrodes modified with multiwalled carbon nanotubes. Sens. Actuators B Chem. 2010, 145, 417-427.

[20] Sims, M. J.; Rees, N. V.; Dickinson, E. J. F.; Compton, R. G. Effects of thin-layer diffusion in the electrochemical detection of nicotine on basal plane pyrolytic graphite (BPPG) electrodes modified with layers of multi-walled carbon nanotubes (MWCNT-BPPG). Sens. Actuators B Chem. 2010, 144, 153-158.

[21] Stankovich, S.; Dikin, D. A.; Piner, R. D.; Kohlhaas, K. A.; Kleinhammes, A.; Jia, Y. Y.; Wu, Y.; Nguyen, S. T.; Ruoff, R. S. Synthesis of graphene-based nanosheets via chemical reduction of exfoliated graphite oxide. Carbon 2007, 45, 1558-1565.

[22] Eda, G.; Fanchini, G.; Chhowalla, M. Large-area ultrathin films of reduced graphene oxide as a transparent and flexible electronic material. Nat. Nanotechnol. 2008, 3, 270-274.

[23] Eda, G.; Chhowalla, M. Chemically derived graphene oxide: Towards large-area thin-film electronics and optoelectronics. Adv. Mater. 2010, 22, 2392-2415.

[24] Stevenson, K. J.; Tschulik, K. A materials driven approach for understanding single entity nano impact electrochemistry. Curr. Opin. Electrochem. 2017, 6, 38-45.

[25] Xu, W.; Zou, G. Q.; Hou, H. S.; Ji, X. B. Single particle electrochemistry of collision. Small 2019, 15, 1804908.

[26] Sokolov, S. V.; Eloul, S.; Kätelhön, E.; Batchelor-McAuley, C.; Compton, R. G. Electrode-particle impacts: A users guide. Phys. Chem. Chem. Phys. 2017, 19, 28-43.

[27] Li, X. T.; Batchelor-McAuley, C.; Whitby, S. A. I.; Tschulik, K.; Shao, L. D.; Compton, R. G. Single nanoparticle voltammetry: Contact modulation of the mediated current. Angew. Chem., Int. Ed. 2016, $55,4296-4299$.

[28] Hummers, Jr. W. S.; Offeman, R. E. Preparation of graphitic oxide. J. Am. Chem. Soc. 1958, 80, 1339.

[29] Ellison, J.; Batchelor-McAuley, C.; Tschulik, K.; Compton, R. G. The use of cylindrical micro-wire electrodes for nano-impact experiments; facilitating the sub-picomolar detection of single nanoparticles. Sens. Actuators B Chem. 2014, 200, 47-52.

[30] Kätelhön, E.; Tanner, E. E. L.; Batchelor-McAuley, C.; Compton, R. G. Destructive nano-impacts: What information can be extracted from spike shapes? Electrochim. Acta 2016, 199, 297-304.

[31] Miao, R. Y.; Chen, L. F.; Shao, L. D.; Zhang, B. S.; Compton, R. G. Electron transfer to decorated graphene oxide particles. Angew. Chem., Int. Ed. 2019, 58, 12549-12552.

[32] Xie, Y. N.; Wang, J.; Huang, X.; Luo, B. W.; Yu, W. Z.; Shao, L. D. Palladium nanoparticles supported on graphene sheets incorporating boron oxides $\left(\mathrm{B}_{x} \mathrm{O}_{y}\right)$ for enhanced formic acid oxidation. Electrochem. Commun. 2017, 74, 48-52.

[33] Krittayavathananon, A.; Srimuk, P.; Luanwuthi, S.; Sawangphruk, M. Palladium nanoparticles decorated on reduced graphene oxide rotating disk electrodes toward ultrasensitive hydrazine detection: Effects of particle size and hydrodynamic diffusion. Anal. Chem. 2014, 86, 12272-12278.

[34] Ejaz, A.; Ahmed, M. S.; Jeon, S. Highly efficient benzylamine functionalized graphene supported palladium for electrocatalytic hydrazine determination. Sens. Actuators B Chem. 2015, 221, 12561263.

[35] Chinchilla, R.; Nájera, C. Chemicals from alkynes with palladium catalysts. Chem. Rev. 2014, 114, 1783-1826.

[36] Serov, A.; Kwak, C. Direct hydrazine fuel cells: A review. Appl. Catal. B Environ. 2010, 98, 1-9.

[37] Zhang, J. H.; Zhou, Y. G. Nano-impact electrochemistry: Analysis of single bioentities. TrAC Trends Anal. Chem. 2020, 123, 115768.

[38] Cheng, W.; Compton, R. G. Electrochemical detection of nanoparticles by "nano-impact" methods. TrAC Trends Anal. Chem. 2014, 58, $79-89$.

[39] Hodson, H.; Li, X. T.; Batchelor-McAuley, C.; Shao, L. D.; Compton, R. G. Single nanotube voltammetry: Current fluctuations are due to physical motion of the nanotube. J. Phys. Chem. C 2016, 120, 6281-6286.

[40] Albery, J. Electrode Kinetics; Clarendon Press: Oxford, 1975.

[41] Compton, R. G.; Banks, C. E. Understanding Voltammetry, 3rd ed.; World Scientific: Singapore, 2018.

[42] Guidelli, R.; Compton, R. G.; Feliu, J. M.; Gileadi, E.; Lipkowski, J.; Schmickler, W.; Trasatti, S. Defining the transfer coefficient in electrochemistry: An assessment (IUPAC technical report). Pure Appl. Chem. 2014, 86, 245-258.

[43] Ram, M. S.; Hupp, J. T. Linear free energy relations for multielectron transfer kinetics: A brief look at the Broensted/Tafel analogy. J. Phys. Chem. 1990, 94, 2378-2380. 
[44] Cutress, I. J.; Compton, R. G. Theory of square, rectangular, and microband electrodes through explicit GPU simulation. J. Electroanal. Chem. 2010, 645, 159-166.

[45] Aoki, K. Theory of ultramicroelectrodes. Electroanalysis 1993, 5, 627-639.

[46] Rudolph, M.; Reddy, D. P.; Feldberg, S. W. A simulator for cyclic voltammetric responses. Anal. Chem. 1994, 66, 589A-600A.

[47] Szabo, A.; Cope, D. K.; Tallman, D. E.; Kovach, P. M.; Wightman, R. M. Chronoamperometric current at hemicylinder and band microelectrodes: Theory and experiment. J. Electroanal. Chem. Interfacial Electrochem. 1987, 217, 417-423.
[48] Kovach, P. M.; Caudill, W. L.; Peters, D. G.; Wightman, R. M. Faradaic electrochemistry at microcylinder, band, and tubular band electrodes. J. Electroanal. Chem. Interfacial Electrochem. 1985, 185, 285-295.

[49] Forster, R. J. Microelectrodes: New dimensions in electrochemistry. Chem. Soc. Rev. 1994, 23, 289-297.

[50] Chidsey, C. E. D. Free energy and temperature dependence of electron transfer at the metal-electrolyte interface. Science 1991, 251, 919-922.

[51] Hush, N. S. Electron transfer in retrospect and prospect 1: Adiabatic electrode processes. J. Electroanal. Chem. 1999, 470, 170-195. 